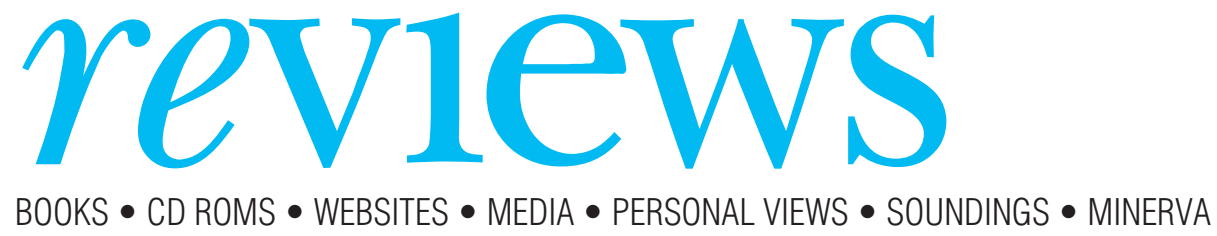

\title{
Desperately Seeking Solutions: Rationing Health Care
}

David J Hunter

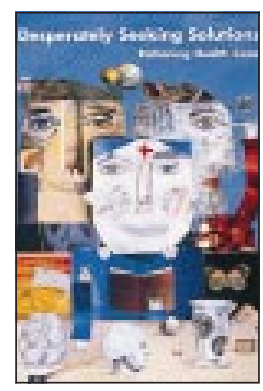

Addison Wesley Longman, $£ 14.99$, pp 176 ISBN 0582289238

Rating: $\star$
$\mathrm{H}$ ealthcare rationing, according to Professor Hunter's summary of the rationing debate, is inevitable and, since the case of "Child B," which exploded the myth that the NHS would pay for any treatment, we all know that it is inevitable. However, rationing is difficult to justify, he says, because society is not yet ready for clear rules about when to deny medical care to people in need of it. The "hard-nosed rational rationers," the ones who seek general principles, may be pursuing an "intellectually irrefutable case," but life is too complex for their explicit approach. Far better, he says, to sustain the irrationality of implicit rationing in the clinical relationship while at the same time insisting that doctors stop acting as patient advocates. If anybody asks, let doctors do the explaining. In other words, give rationing the cloak of medical respectability.

But the Child B case did not explode any myths. On the contrary, the health authority called it a decision made in the best interests of the child. The rationers' case is intellectually refutable because no single deductive principle can govern medical decision making, and it is a mistake to suppose otherwise. Reasoning on a case by case basis is not irrational, it is about deciding what to do for the good of the patient. The American experience of litigation over managed care provides ample evidence of the pitfalls of confounding health care with corporate resource management. And there is much more to be said about the reopened anti-NHS argument of the 1940 s, the "insatiable demand" argument, which predicted (inaccurately) that a service free at the point of need would be swamped. For example, Hunter's historical account fails to consider the huge surge in private healthcare investment since the mid-1980s. Curtailing a comprehensive service in this context has the effect of making room for private enterprise.

In Hunter's account there are no right answers; the object is to rationalise decisions already made, and it is acceptable to leave open to question whether a person in need of medical care should receive it. This should be hard to swallow for a profession dedicated to different ends and involved in actions which have real and pressing consequences.

David Price, research fellow, Social Welfare

Research Unit, University of Northumbria

\section{Gout: The Patrician Malady}

Roy Porter, G S Rousseau

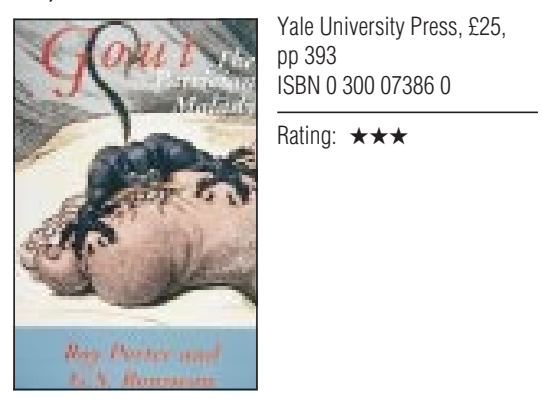

$\checkmark$ out has been recognised since antiquity, and descriptions of the disease date back to the Babylonian empire. It was certainly well described by Hippocrates. Called the "king of diseases" and the "disease of kings", gout is more the "disease of plenty." In Gout Porter and Rousseau track medical thinking about the disease across the centuries, from Hippocrates and Galen to Paracelsus, Harvey, Archibald Garrod in the Victorian era, and beyond. They discuss the cultural, moral, religious, and personal qualities associated with the condition, examining social commentary, personal writings, cartoons and visual arts, and literature (including novels by Dickens, Thackeray, and Joseph Conrad).
Many of the quotations still ring true: "gout the bitter fruit of luxury" (Cheyne), "the seeds of this evil are frequently derived from the parents!" (Blackmore), "those most vulnerable were men with hail and athletic constitution," who must pursue "abstinence in eating, temperance in drinking strong liquors and proper exercise." Folklore deemed gout a disease of the better sort, a superiority tax, a celebrity complaint "fit for a man of quality." Gout was the distemper of a gentleman whereas the rheumatism was the distemper of a hackney coachman.

In addition, gout was viewed by Georgian doctors such as Walpole "as one of the nature's solutions to depravities of the humours. If not entirely expelled, peccant humours or morbific matter were exiled to far-flung parts. Hence it should be left to do its work." Gout could be seen as a desideratum, a life insurance rather than a death sentence. While gout was in possession of the body, no truly deadly enemy such as palsy, dropsy, or apoplexy could strike.

However, Walpole's contemporary Samuel Johnson pursued quite different strategies: "That the gout is a medicine I never perceived, for when I had it most in my foot, I had the spasms in my breast. At best the gout is only a dog that drives the wolf away and eats the sheep himself, for if the gout has time for growth, it will certainly destroy and destroy by long and lingering torture."

King George IV mutinied against the royal physicians' policy of “quieta non movere" and phlebotomy: "I have borne your half measures long enough to please you; now I shall please myself and take colchicum."

Gout has been the sign of distinction, the patrician malady to top all others. One of the aims of this book is to delve deeply into how people come to "choose" to be ill and, being ill, which sickness they select and how they sell it. In this inquiry Porter and Rousseau explore in an exemplary manner medical writings, literary texts, journals and diaries, and the visual arts.

Weaving these threads together, the authors provide an enjoyable account that integrates the medical and the moral, the scientific and the humanistic, the verbal and the visual across an impressive sweep of time. Although recently published, the book's appearance has the flavour of the 1950 s, with old fashioned notes (40 pages) and an extensive bibliography and index that historians will love.

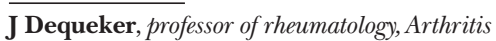
and Metabolic Bone Disease Research Unit, Katholieke Universiteit Leuven, Belgium

Reviews are rated on a 4 star scale

(4=excellent) 
Step by Step Guide to Epidemiological Health

Needs Assessment for Ethnic Minority Groups

J Mackintosh, R Bhopal, N Unwin, N Ahmad

University of Newcastle, £10, pp 99 ISBN 0701700793

\section{Dying, Death and}

Bereavement in a British Hindu Community

S Firth

Peeters, £17.99, pp 240

ISBN 9068319760

Rating: $\star \star, \star \star \star$

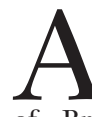
s we celebrate the 50th anniversary of the founding of the NHS we should also reflect on the growth of Britain's black and ethnic minority population. These two elements of modern British society have not only grown up together but are also intimately related. During the late 1940 s and '50s there was a major recruitment drive of doctors and nurses from Commonwealth countries to work in the "mother country." Some years later their dependants joined them, and during the 1960s events in Africa led to an influx of "Asian" migrants. The ethnic minorities now form $6 \%$ of the British population, and within this figure there is enormous cultural diversity.
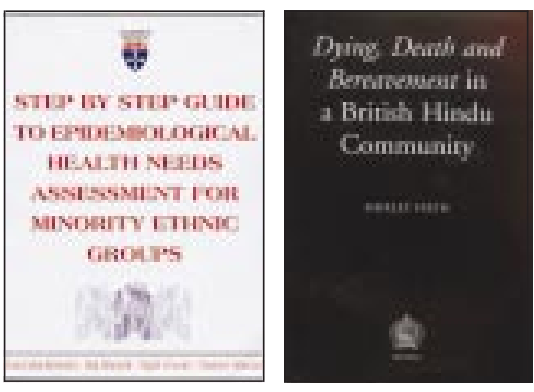

Healthcare needs assessment is a relatively new term for an older concept and is defined pragmatically as the ability to benefit from health care. The Step by Step Guide takes us through the process of assessing needs; it covers difficult areas, such as defining ethnicity and "race," which the authors illustrate by defining their own ethnic group. The issue of ethnocentricity, when the view of the majority is used as the standard against which others are compared, is highlighted by the problems of standardising rates for specific ethnic groups. I enjoyed reading this guide, which states the objectives for each chapter and provides worked examples. As this is a basic introduction, it lacks details on specific ethnic groups and diseases, but the appendix provides further sources of help. Some of the material can be adapted for teaching at both undergraduate and postgraduate levels.

Whereas the Step by Step Guide provides an overview of minority ethnic groups, Dying, Death and Bereavement focuses on a specific minority group and subject. The book arose from the author's thesis and compares the beliefs and practices of death of British Hindus with their counterparts in India. The author collected data for this by spending three months in India. The focus of the book is individual Hindus, seen in the context of their family and community. The first part sets the context and provides a cross cultural perspective of death and bereavement. As Firth reminds us, "In a secular culture in which death is highly medicalised, there is a risk of seeking rational explanations for illness and death in terms of physical causes which can lead to separation of religion from the rest of life and a devaluation of religious experience and spirituality." So the Hindu model of a "good death" provides a useful philosophical approach to death, with new insights and understanding.

Rituals around death are explored in the second part, and the book concludes with an analysis of the social and psychological dimensions of death and mourning and implications for professionals in this country. The book also gives a lucid account of Hinduism and how British Hindus have adapted these "practices."

In the constantly changing NHS both these resources will be valuable to both commissioners and providers of services, as well as academics. Indeed, Dying, Death and Bereavement will also be of help to those wanting deeper insight, and it shows that the host community also needs to learn and adapt.

Paramjit S Gill, senior lecturer, Department of General Practice, University of Birmingham

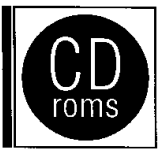

\section{Minor Surgery and Skin} Lesions: Diagnosis and Management on CD-ROM

Roger Kneebone, Julia Schofield

Primal Pictures, London, $£ 65$

ISBN 1902470052

Rating: $\star \star \star$

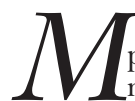

inor Surgery and Skin Lesions presents in a spectacular way Iminor surgical techniques, and I have never seen them illustrated before with such clarity. The cartoon-like animations and the clear sound track answer many questions that, because of their apparent simplicity, are never asked lest the questioner betrays his ignorance, like the emperor's new clothes. Having practised minor surgery in general practice for 30 years, I found new solutions to many simple problems that I tackled with what I thought was common sense, which is the enemy, I fear, of progress.

Minor surgery has become much more important to general practitioners, who are being encouraged for many reasons to carry out these minor procedures in their practices. Apart from being lucrative, minor surgery is a satisfying aspect of general practice. This CD Rom will also appeal to junior hospital medical staff, who are often thrown in at the deep end by their senior surgical colleagues and expected to carry out minor surgery lists with little training or supervision.

I learnt several simple but valuable points, such as the optimum ratio between the length and width of an ellipse excision and that the excision should be started at the apices and extend to the middle, which may be obvious but need stressing and quantify-

To order any books reviewed here contact the BMJ Bookshop, BMA House, Tavistock Square, London WC1H 9JR.

Tel 0171383 6244. Fax 01713836455.

email: orders@bmjbookshop.com.

You can pay by cheque in sterling drawn on a

UK bank or credit card (Mastercard, Visa, or

American Express) stating number, expiry date, and full name. ing. The medicolegal precautions that need to be taken were dealt with succinctly, as were many other aspects of medical practice. The exact anticipated size of any resultant scar and the possibility of a keloid forming must be carefully explained to patients beforehand.

The humility born of great experience shows itself clearly in the patient education leaflet, and in the advice to send all removed tissue for histology no matter how benign the lesion may seem. The authors' backgrounds -a surgeon who became a general practitioner and a general practitioner who became a dermatologist-may account for the breadth of understanding of the topic.

The only flaw was the frustration of having to transfer from the main text to illustrations and related matters through the red and orange icons, but this drawback may be of little importance when using this $\mathrm{CD}$ as a reference source. Apart from this minor quibble, I found that Minor Surgery and Skin Lesions presents much factual information in a very agreeable and enjoyable form.

M A Casson, general practitioner, Didsbury,

Manchester 


\section{Tit}

\section{Shock to stop?}

\section{Massachusetts'antismoking campaign}

$\mathrm{P}$ am Laffin, a 29 year old mother of two, is the latest weapon in the US health sector's war on the tobacco industry. Mrs Laffin's struggle to survive emphysema is being shown on prime time television in Massachusetts in a series of 30 second antismoking advertisements.

Paid for by the state's Department of Public Health, the media campaign reveals that she is waiting for a second lung transplant, her body having rejected the first. It also features a comparison of a healthy lung and a tobacco ravaged lung, and displays the woman's transplant scar. Costing $\$ 1.5 \mathrm{~m}(£ 0.9 \mathrm{~m})$, these advertisements are intended to grab the attention of smokers who need more urging to quit and young people who are just starting to smoke.

The Massachusetts adverts reflect a trend started by an Australian campaign in 1997 that used scare tactics to target smokers aged 18-39. The adverts in this campaign began with smokers lighting up, followed by smoke coursing through bronchial tubes, and ended with a particularly gory scene of an aorta spewing fatty deposits. The message was: "Every cigarette is doing you damage."

But what are these adverts doing? Are they having any effect on reducing smoking, or are they simply gaining attention for the organisations that are sponsoring them? In Australia it has been reported that the "jury is still out" but that there are "early signs" from telephone interviews that more people were talking about the campaign and that there was "increased activity toward quitting." In Massachusetts it has been reported that calls to the state's antismoking counselling service have increased sixfold. But people talking about adverts or making telephone inquiries are a far cry from reducing smoking prevalence. This is hardly compelling evidence that this approach will have any greater effect on smoking behaviour than others have in the past.

The term "mass media" carries the promise of reaching all with a single message, but the situation is considerably more complex, as any good marketing expert can testify. There are many different audience segments, and the variety of widely available, special interest programming has expanded dramatically. As audience segments become increasingly split into smaller units, new opportunities emerge for specialised health messages addressing these segments.

Smokers comprise several audience segments. They include both old and young, with vastly different communication styles and perspectives on smoking. Perhaps the new adverts based on fear are just right to jar into immediate action an older smoker who has been considering quitting and might have stopped smoking in the near future even without seeing this message What effect do these messages have on the much larger group of smokers who are not even thinking about quitting, and what help do they offer those who are currently trying to quit or stay quit?

Youths who do not yet smoke comprise other segments. The period of highest risk for starting smoking falls between preadolescence and the mid-teens. The social and cultural differences between ages 10 and 15 can be as impressive as the physical differences; different developmental trajectories by sex enliven this picture further. The relevance of messages featuring an elderly looking hospital patient or an oozing aorta could easily be missed by a 10 year old boy mainly interested in motorcycle racing and professional wrestling.

Although message styles need to differ substantially, educational strategies for smoking prevention that have been tested in controlled studies clearly point to guidelines that apply across these differences. These guidelines emphasise the importance of social influences, both positive and negative, on a young person's decisions about becoming a smoker. Since we have educational models that can be used to design and evaluate effective campaigns, why aren't they being applied in the war against tobacco? The Australian campaign has
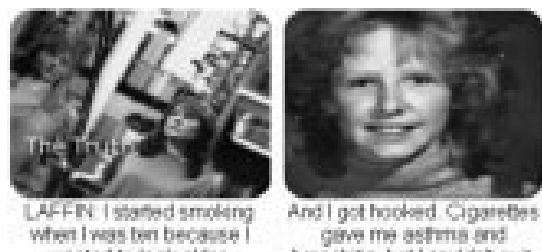
Andi got hocked Cigare
gave me astims and monchis but icoudit an
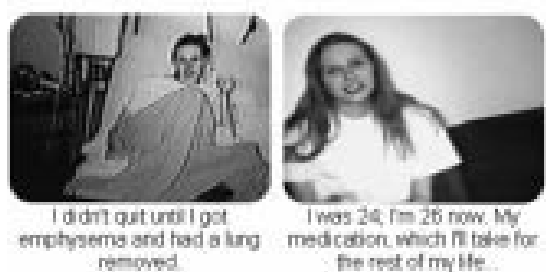

tysems and had removed

Pam Laffin, on TV and the web (www.cdc.gov/nccdphp/osh/mcrc/laffin.htm)

made a serious attempt at using some of these models in designing their campaign, but the designers report no rigorous evaluation.

With the advent of settlements from tobacco companies, many governments are on the verge of making huge investments in antismoking media campaigns. It is time to stop improvising with messages that appeal primarily to antismoking advocates and executives of advertising agencies. Until we do, we will continue to waste a potentially powerful weapon in the war against tobacco.

John Worden and Brian Flynn, research professors, Office of Health Promotion Research, University of Vermont, Burlington, USA

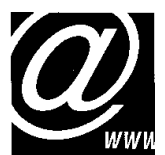

WEBSITE OF THE WEEK

Douglas Carnall dcarnall@ bmj.com http://www.database.is/ News of a government planning to sell the genetic information of its entire population to a single company (DeCODE) must raise a few eyebrows among those concerned about civil liberties (see News, p 11). DeCODE plans to amalgamate the detailed genealogical records that the Icelandic people have traditionally kept with state medical records and genetic information. It will then sell access to its database as a research tool for drug companies.

The website set up to convince the public of the sense of the proposals incorporates some heavy duty content: for example, DeCODE's informatics director Guzbjartsson outlines the specification for the security of the database (in a single HTML page of about 6000 words). This is poor internet manners: if you must present that much information to your users you should offer them a PDF file to download that will print nicely.

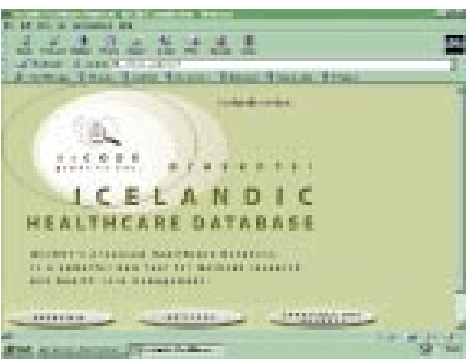

The site does not give server space to the opposition but makes an oblique reference to its presence: it has a link that promises a "Response to Ross Anderson," although there is no link to Anderson's report itself. In fact, Dr Anderson, the Cambridge computer scientist who has in the past advised the BMA on data protection, is easy to find: his pages live at the desirable address of http://www.cl.cam.ac.uk/users/rja14/. His use of HTML is clear, and his criticism that systems that record longitudinal health data can never be fully anonymised is convincing. The Icelandic Medical Association, which commissioned him to produce the report, also has a presence on the web, at http://www.icemed.is/, but you'll have to brush up your Icelandic if you want to read its site. 
PERSONAL VIEW

\section{My route to a steroid psychosis}

I n November 1997 a renal biopsy showed the pathognomic signs of Goodpasture's syndrome. Eight months earlier I had had a mysterious septicaemic illness for which no aetiological agent was ever found and from which I apparently recovered.

However, over the ensuing months the antiglomerular basement membrane (antiGBM) antibodies were silently accumulating until they reached levels that were off the measurable scale. By the time I presented to the renal unit at Manchester Royal Infirmary, my renal function was terminally compromised.

The therapeutic plan adopted a threefold approach. Firstly, switch off the antibody production using cyclophosphamide 150 mgs daily. Secondly, remove the existing antibodies by a process of immunoabsorption. The machines for this procedure are few and far between and rarely used. Goodpasture's syndrome is in itself a rare disease-only one person in a million develops it each year. The third part of the strategy was to protect my remaining nephrons from the dangerously high levels of destructive antibody using a large dose of prednisolone (60 mgs daily for a few weeks).

It is the effects of the steroids on my psyche that is the subject of this personal view. My sense of humour has always been a little "off the wall" and occasionally unfamiliar people are unsure about some of my jokes.

The first stage of my steroid psychosis was characterised by garrulous euphoria and an urge to write prolifically. Those who knew me well might have had difficulty in distinguishing between what was abnormal behaviour and what was "just me." In fact one of the senior registrars asked my wife, "Is he normally like this?" Just before Christmas the general practitioners' negotiators telephoned me from a restaurant on a mobile phone. I think their intention was to wish me a quick season's greetings and a speedy recovery. But I surprised them with a vibrant and upbeat response which ended only after 20 minutes when the phone's batteries gave out.

But there was one night in January which my wife and daughter would rather not be reminded of. I was due for an immunoabsorption session because the anti-GBM antibodies were climbing again. The nurse-my guardian angel-the only

If you would like to submit a personal view please send no more than 850 words to the Editor, BMJ, BMA House, Tavistock Square, London WC1H 9JR or e-mail editor@bmj.com nurse, or doctor for that matter, who knew how to operate the immunoabsorption machine, was taken ill. There are fewer than 10 nurses with this skill in England. The doctors decided that the antibodies must not be allowed to stay at this new level without some intervention, and recommended plasmapheresis, which though not as specific or as efficient at eliminating the antibodies, would at least remove some. When I was receiving this treatment I developed my usual symptoms of a burning face and rigors. It was thought that this was a reaction to the plasmapheresis and I was given a bolus of $100 \mathrm{mgs}$ of intravenous hydrocortisone.

That night really saw me "away with the fairies." The highlight of this terrible night was when I tried to telephone my son in law on my electric razor. I was quite happy doing this but my family was distraught. It is amazing how much I remember of this period. To me my thoughts and consequential conversation were quite logical.

Unfortunately others did not share the logic, and when they would not listen to me I had to shout to get my point across. When my bed was surrounded by the medical team, I felt like a fish in a pond looking up at the people standing on its edge not knowing how best to influence them in the discussions they were having about me. They seemed to be ignoring me. I could catch their attention only by struggling against gravity and my weakness to raise myself up-"to poke my head out of the water"-and make what you might call very direct remarks, which they inevitably interpreted as "irrational shouting."

This period passed after a few weeks as the steroids were stopped. I was then seen by the psychiatrist who had the difficult job of determining whether I was back to normal.

I realise that I have had a better outcome than many patients with end stage renal failure. At least, despite a turbulent three months in isolation, I now look well and there are so many of my fellow patients who do not.

Feeling well is another matter, but even the disease free among us cannot always be so blessed. So as I slowly get used to my thrice weekly sessions of haemodialysis, I look forward to the day when a donor kidney becomes available for me, which will restore to me and my family the freedom to participate in normal lives again.

Simon Jenkins, general practitioner, Bury

\section{BOOKCASE}

- The caustic jibe about using statistics like drunkards use lamp posts-for support rather than for

illumination-might have been aimed at doctors. Fortunately, perhaps, statisticians are hard to discourage, and they continue to write what they imagine are straightforward accounts of their subject for the less numerate. Mould's Introductory Medical Statistics (Institute of Physics Publishing, £27, ISBN 075035134 ) is more ambitious than most. It includes, for example, a chapter on the Cox proportional hazards model.

- Professional historians of medicine tend to scorn the efforts of amateurs, especially the retired consultant who writes the history of his or her specialty. They object, I suppose, to the way in which the doctor always gets the hero's role in the narrative. But traditionalists will enjoy John Hughlings Jackson: Father of English Neurology (Oxford University Press, £39.50, ISBN 019512339 5). The biographers are the late Macdonald Critchley, himself a renowned neurologist, and his wife Eileen Critchley.

- Systematic literature reviews have multiplied with amazing speed over the past decade. The methodology for searching bibliographic databases, appraising individual studies, and summarising data continues to be developed. Mulrow and Cook have put together a useful summary of the current state of play in Systematic Reviews: Synthesis of Best Evidence for Health Care Decisions (American College of Physicians, $\$ 27$, ISBN 094312666 5). It is brief, clearly written, and, best of all, is firmly oriented towards patient care.

- Although both specialties deal with the same organ system, the gap between neurology and psychiatry sometimes seems unbridgeable. The application of new techniques, particularly those of brain imaging, are starting to raise questions about this organic-functional dichotomy. In Disorders of Brain and Mind (Cambridge University Press, £55, ISBN 052147306 3) Ron and David have collected contributions from both laboratory and clinical scientists to illustrate aspects of neuroscience where ideas about brain and mind are converging.

- Psoriasis is a common but complex disease. Its causation remains obscure, although experts agree that the clinical lesions are the result of hyperproliferation and abnormal differentiation of the epidermis. Treatment has improved strikingly in recent years, and the short Handbook of Psoriasis (Blackwell Science, £29.50, ISBN 086542558 2) explains, among other things, the rational use of vitamin D analogues, retinoids, topical corticosteroids, and other treatments.

Christopher Martyn, $B M J$ 